\title{
Freshwater pH Level Control and GUI System for Prawn Breeding
}

\author{
Muhammad Naqiuddin Mohamad Yasin, Meor Mohd Azreen Meor Hamzah, Murizah Kassim, Norakmar Arbain \\ Faculty of Electrical Engineering, Universiti Teknologi MARA, 40450 UiTM Shah Alam, Selangor, Malaysia. \\ norakmar7222@uitm.edu.my
}

\begin{abstract}
Prawn culture is one developing area of the aquaculture in Malaysia towards water quality monitoring good health of aquatic ecosystems for prawn habitats. Currently, prawn farmer in Asian country still applied a manual technique to add chemicals to control the $\mathrm{pH}$ water level. Automation system is needed to switch them to automatic techniques to manage water $\mathrm{pH}$ level. This research has designed a control and monitoring system of $\mathrm{pH}$ level. The $\mathrm{pH}$ water reading data are stored in a database and an automated system reacted to change and control the $\mathrm{pH}$ water level either alkaline or acidic is designed based on the data captured. Concentrated on observation and controlling the $\mathrm{pH}$ level is measured. Graphical User Interface computer program with Visual $\mathrm{C}$ is used in the system to monitor and control the status of prawn tank supported. Admin will interact with electronic devices through GUI interface and visual indicator to control the tank condition. The system is designed using Arduino Uno controller to manage the flow control to analyses feedback signal from a $\mathrm{pH}$ detector that measured the value of the $\mathrm{pH}$ level in the water and controlled method executed between bases alkaline and acidic water level. Results present an extended $\mathrm{pH}$ changes depends on the higher concentration of alkaline or acids. Pumped-up of water actions using the pump is automatically moved to maintain back the $\mathrm{pH}$ level at ideal and optimum condition. The development of control system mechanism on water $\mathrm{pH}$ level is produced for higher growth of prawn and low cost of force in the market. This research significant and helps towards small-scale farmers for prawn breeding.
\end{abstract}

Key words: Arduino Uno, Freshwater $\mathrm{pH}$ level Controller, GUI System, Prawn Breeding, pH Sensor.

\section{INTRODUCTION}

Aquaculture is the cultivating of sea-going living being in nature of controlled marine or freshwater conditions. The examination presents aquaculture industry is blossoming quickly over the most recent 20 years and it has been recognized as the most well-known technique in the fishery sector [1]. However, water quality is the primary factor in deciding the achievement or disappointment of aquaculture cultivating. Continuous exchange of a small proportion of the water is the normal way of maintaining good water quality caused by low dissolved oxygen factors [2]. The research presents in intensive shrimp or prawn farming systems; formulated feed represents the main nutrition source and its adequate management significantly influences the economic feasibility of the farm. Based on that, the present study evaluated two dynamic feeding strategies: fuzzy logic (FL) and mathematical functions (MF) has been done [3].

A studied in Malaysia presents control, monitoring and culturing prawns needs a specific $\mathrm{pH}$ level control of water in prawn pond. The suitable $\mathrm{pH}$ level is exactly the same with $\mathrm{pH}$ of seawater which is at $6.0-8.5$ unit where the optimum or recommended $\mathrm{pH}$ level is at $6.5-8.5$ [4]. This is important when culturing prawns to make sure it grows healthier and reduce mortality of prawns due to uncontrolled $\mathrm{pH}$ level. Prawn culture is the fastest growing sector of the aquaculture industry in Malaysia like tiger prawn; the $\mathrm{pH}$ level needed for water is around 7.0-8.5. Currently, prawn farmer in Malaysia still using a manual method to control the water $\mathrm{pH}$ level by adding lime chemical for the process required constant monitoring and control by labor. Since the prawns are so sensitive on $\mathrm{pH}$ level, an automatic $\mathrm{pH}$ control system is required to maintain the water $\mathrm{pH}$ automatically and precisely [5, 6]. One research presents the Cloud-based smart water quality monitoring system using IoT sensors and machine learning. The proposed framework predicts the water quality and assesses the performance of the decision tree classifier. Decision Tree is used to infer decision rules based on various parameters read through sensors[7]. Many systems with IoT implemented platform has been done today to cater data accessed and IR4.0 technology in advanced agriculture such as fish farming[8], automated fish feeder and water quality detection[9], distribution of wind speed as preliminary information for fishers[10], Milkfish freshness detection utilizing Coiflet wavelet transform method[11].

Monitoring activity includes inspection is manually done examples of ammonia level, $\mathrm{pH}$ level and dissolved oxygen (DO) in water. Workers need to take a few samples of the water and perform the required test and took between ten to fifteen minutes to accomplish it. Sometimes, the test will need to be repeated is samples used are spoiled or no usable. The process is taken a long time and cost manpower consuming. Therefore, to solve the problems, designing control and maintain mechanism $\mathrm{pH}$ levels in water for prawn breeding were proposed. It has been discovered that aquaculture farms have requested for an IT system that can monitor the aquaculture environment and alert the users when inadequate environmental situation develop. Thus, the paper aims to present the details of design and implementation of level $\mathrm{pH}$ water control and maintaining system in prawn pond freshwater farming. Internet of Things (IoT) with automation system method which controls and monitor some precise amount of chemical can be added to 
the pond. Thus, level of $\mathrm{pH}$ in water is controlled technologically like wireless sensor network system. The system equipped with an alert feature from a graphical user interface (GUI) to inform the farmer of the $\mathrm{pH}$ level in the water. The concept of the automation system in prawn breeding can help our farmer in the aquaculture industry to reduce cost and increase productivity.

\section{LITERATURE REVIEW}

Numerous ongoing sorts of research identified with prawn breeding's and the system framework where new innovations towards prawn reproducing are imperative. An investigation was done to assess the impact of providing thickness on gainful execution of freshwater prawn on Macro brachium rosenbergii in bio floc framework is done [12]. Freshwater prawn cultivating possesses a conspicuous spot among aquaculture exercises. The most recent information by FAO indicated generation of roughly 500,000 ton of freshwater prawn, with features for the species Macro brachium rosenbergii and Macro brachium Nipponese [13]. Another comparative study for aquaculture prawn is on flexible link aerator using Arduino programming and dissolved oxygen meter was done. The aquatic lives may have the issue to acquire reasonable disintegrated oxygen in the water and by utilizing the aerator system, it will be dissolved oxygen naturally. The aerator framework just creates dissolved oxygen then the Arduino is included for controlling the rate of disintegrated oxygen in Prawn Lake. The volume of dissolved oxygen in the water for aquatic lives is the parameter that should be constrained by Arduino [14]. Research on physical and synthetic attributes of soil from tiger shrimp aquaculture lakes at Malacca, Malaysia was done [15]. Soil physicochemical properties of the developed lakes of black tiger shrimp (Penaeus monodon) were analyzed in connection to shrimp yields for one generation cycle. The outcomes show that shrimp lake age may not influence the generation of shrimp if soils are legitimately overseen for the pre-and post-culture. The distinctions underway in various lakes may be the after effect of the management practice, for example, nature of shrimp post hatchlings, lake readiness, water, and feed quality, and accessible live feed in the lake base or other ecological variables like water supplements and physicochemical parameters. Along these lines, observing water quality is essential.

Checking Aquaculture Water Quality, Structure of an Early Cautioning Sensor with Aliivibrio fischeri (AF) and Prescient Models was done [16]. Water checking and control are generally created for aquaculture adventures. A novel toxicity-warning sensor for water quality observing in recycling aquaculture frameworks (RAS) is introduced. The plan of the sensor framework predominantly involves an entire cell-biosensor. AF is a luminescent bacterium generally utilized in danger examination, was tried for a blend of known fish-wellbeing stressors, to be specific nitrite, un-ionized ammonia, copper, aluminum, and zinc. Programmed Water Contamination Control and Filtration Framework for Waterways Utilizing IOT is done. The regularly utilized technique for testing water quality is to assemble tests of water and send to the lab to test and examine. This strategy is tedious and squandered of labor. In these frameworks an IoT gadgets are utilized which help to oversee and breaks down the water parameter to control the water contamination. Sensors put in the waterways which constantly educates the water parameters esteems at the ebb and flow time. This data is refreshed on the cloud and utilizing a page, the client can get to this water parameter on a smartphone or on the site page anyplace that is associated with Web $[17,18]$.

\section{METHODOLOGY}

A controller has been designed to control and maintain a mechanism of $\mathrm{pH}$ level in water for prawn breeding. Figure 1 shows a system framework for the designed controller and program algorithm. It consists of four components which are input and data acquisition, evaluation \& inference, communication, and result of output. The framework algorithm served as the guideline to develop the system architecture of the system, its components, and their interaction between of them.

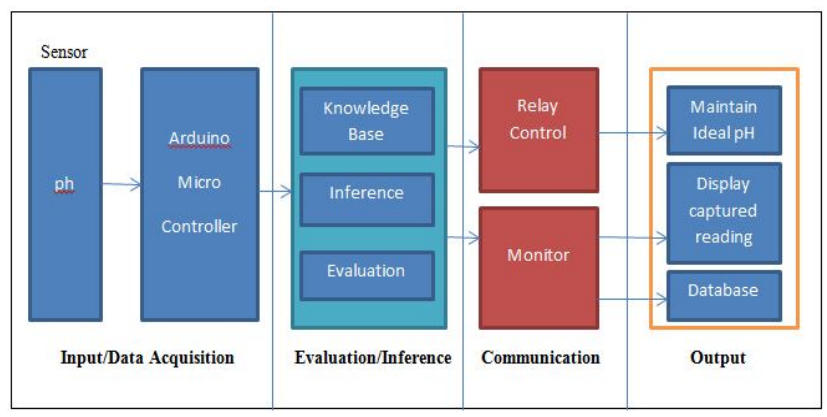

Figure 1: System Framework Algorithm

\subsection{Hardware and Software}

The hardware consists of input and Data Acquisition. This component consists of two parts namely sensor and Arduino Uno microcontroller as data acquisition kit from the sensor. The component is built to distinguish the perusing of the sensor from the pond and the reading would be gathered or received by Arduino Uno. The Arduino Uno is also responsible to convert analog signal to digital signal from $\mathrm{pH}$ sensor suit for PC dissecting. Assessment and induction are an essential segment in this undertaking. This part comprises of three sub-segments which are learning base, surmising, and assessment. The primary sub-parts are utilized to store all received data from data acquisition kit which is Arduino Uno. Real Time data received would be fed into the Inference sub-component to determine tolerable range for $\mathrm{pH}$ parameter. At that point, the assessment is the procedure that decides if the status of $\mathrm{pH}$ level in water meets indicated criteria which are bases, nonpartisan and corrosive. Assessment is done by utilizing the derivation results and the characterized guideline dependent on source code c programming in Arduino Uno.

Communication component is the other part where it isolates into two relying upon the sort of derivation results. The Communication is connected between the transfer controller and PC towards Arduino Uno. On the off chance that the $\mathrm{pH}$ water is inside a middle of the road extend, the information is shown on the screen or else, it is to decide by relay control where the where the motor will pump the chemical either acid or bases. Its purposes is to keep up water at ideal $\mathrm{pH}$ level. Results can be seen on the screen with this system. Then, a result of viewed on a monitor is recorded and saved as a database for references. Lastly, an output of the component retrieved results in three methods 
which are maintained ideal $\mathrm{pH}$ by pump chemical substance in water, display captured reading, monitored, and store the reading result in a database.

\subsection{System Component}

Tools used to develop this system comprise both software and hardware. Arduino C Language is used to compile the program into a microcontroller. The program is divided into three main parts which are structure, variables, and function. The programming contains a control structure, arithmetic operation, comparison operators and digital I/O. Microsoft Visual $\mathrm{C}$ is used as the programming language to create the user interface as well as to implement the data processing feature of the system. The programming is simple, modern, general-purpose, object-oriented program language and easy to handle. The hardware of the system consists of two parts; data acquisition kit which is Arduino Uno and communication system consists of a monitor and relay control system. The hardware design phase would focus on interfacing sensors with the monitor, control and maintaining the system. $\mathrm{pH}$ Sensor is to detect and measure the value of $\mathrm{pH}$ in water. This sensor placed at pond whereas to control $\mathrm{pH}$ level in water for prawn breeding. The output of this sensor is in millivolt $(\mathrm{mV})$. The obtained output in $\mathrm{pH}$ value is to convert the output from millivolt $\mathrm{pH}$ by equation 1 [19].

$$
\mathrm{pH} \text { value }=7-\text { output } 59.16 \mathrm{mv}
$$

The output from the sensor in millivolt will automatically convert into $\mathrm{pH}$ value after these formulas apply in programming. Arduino Uno is acting as a controller to control most of Input and Output components. It decided and gave an output based on the parameter that been set. Parameters are set through source codes that have been programmed to the controller. However, the advantages of the controller that is used can read digital and analog signal. The controller will give output to GUI from analog signal to digital signal from $\mathrm{pH}$ sensor. A relay is the communication system that helps control the motor pump water from microcontroller output. It is an electrically operated switch. This relay is used as a switch to turn on the motor water pump when it is triggered. Besides that, the system is used normally open relay, which is there is an open contact when the relay is not energized or triggered. Relays are generally used to switch smaller currents in a control circuit. A water pump is to pump chemical water either bases or acid to the pond when $\mathrm{pH}$ water is unstable or not on a neutral state. The water pump will start to pump when $\mathrm{pH}$ drops to 6.49 units or increase to 8.51 units. The water pump will turn off when the water in pond turns neutral state which is 6.5 units until 8.5 units.

\subsection{System Flowchart}

Figure 2 shows the system flowchart that explains the steps taken in the system to collect data, analyses and produce results. A process flow of a program is programmed in Arduino Uno started with the initialized program on the output and input pin on Arduino Uno that interfacing computer serial port with Arduino Uno using a USB cable. The Baud Rate is set up for the speed of data transmission in the system between microcontroller and computer. GUI interface is set ready to receive communication and data transfer. Data of real-time on $\mathrm{pH}$ level and condition of $\mathrm{pH}$ Alkaline, Acidic and Neutral is recorded and monitored through a GUI desktop. Graph of $\mathrm{pH}$ level versus with time in seconds is displayed continuously while the program is connected.

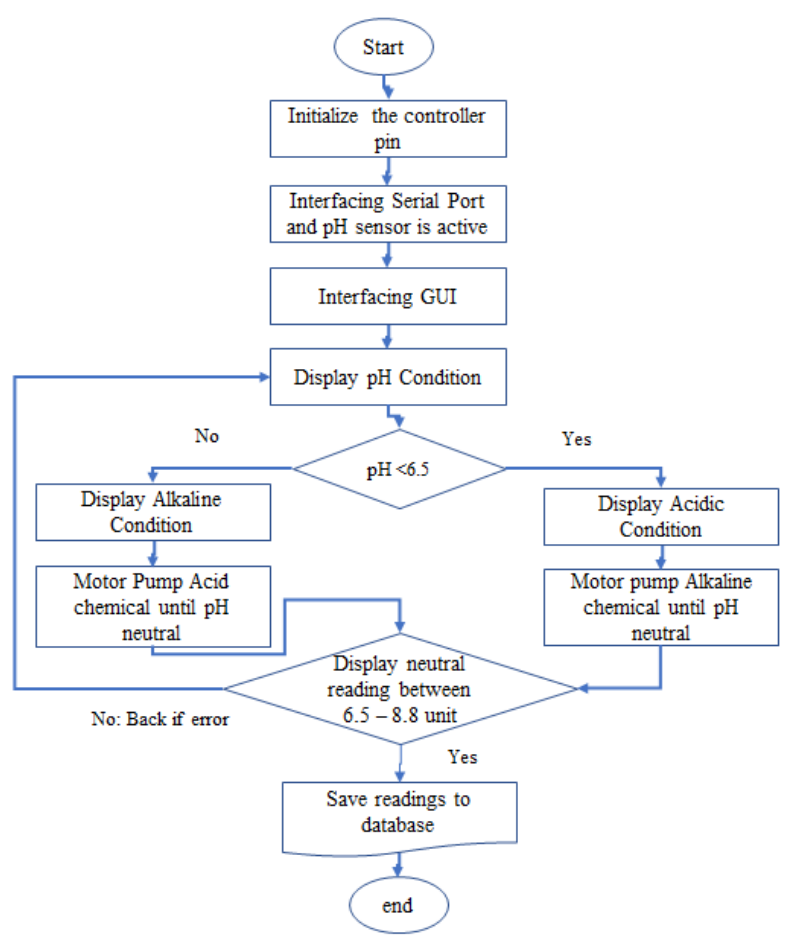

Figure 2: Process flow of the system

Ideal $\mathrm{pH}$ level for freshwater prawn breeding is within tolerable range at 6.5 units until 8.5 unit. So, the water pump is OFF but the reading continuously operated. However, if the $\mathrm{pH}$ level drop to 6.49 units and below the water indicated as acidic cause the water is exposed to an acidic substance, for example, Ammonia. Therefore, the bases chemical is pumped to the pond and neutralized back to optimum $\mathrm{pH}$ level and display the status $\mathrm{pH}$ level on GUI. If $\mathrm{pH}$ readings increase to 8.51 and above, it is identified that the water $\mathrm{pH}$ in the pond is an alkaline state. So, the operation will vice versa. The acidic chemical is pumped into the pond and at the same time, it displays the status condition of water on GUI. The operation is continued until it achieved a neutral state. Finally, data reading from $\mathrm{pH}$ sensor is collected and saved into a computer database system in text format. This operation is continuously operated until the program is disconnected.

\subsection{Block Diagram}

Figure 3 shows a block diagram process of control and maintain $\mathrm{pH}$ level in water for prawn breeding. $\mathrm{pH}$ sensor is operated as input that transmitted the analog signal to the Arduino Uno microcontroller. The signal is converted to digital to produced output reading on water condition and presented in GUI platform. Then, the output reading from Water condition can be monitored in the system and relay is operated based when changes of $\mathrm{pH}$ level in water are identified. The relay will on the motor pump by short circuit method. The Arduino Uno sends pulse ' 1 ' which means $3.5 \mathrm{v}$ to $5 \mathrm{v}$ to on the relay switch. If the water change state from neutral to acid, the bases pump is operated. While, if the water changes state from neutral to alkaline, the acid pump 
then is operated. The operations of both pumps are continued operated until the water back to the neutral state.

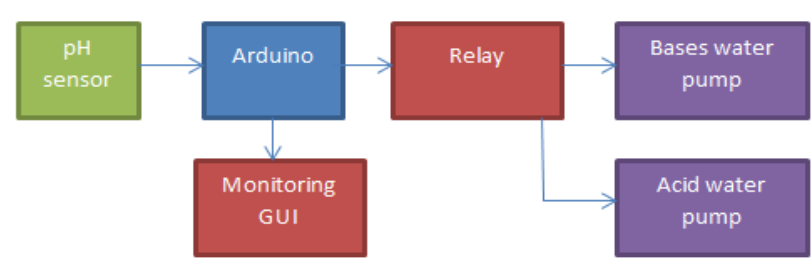

Figure 3: Block Diagram of System

\subsection{Circuit Design}

Figure 4 shows the full circuit design of this project. These circuit designs consist of input and output components. The input of the circuit has a $\mathrm{pH}$ sensor and a $\mathrm{pH}$ circuit module, and the output of circuit design has a relay and water pump. The Arduino Uno act as a microcontroller to control the system of input and output depends on the programming flow process.

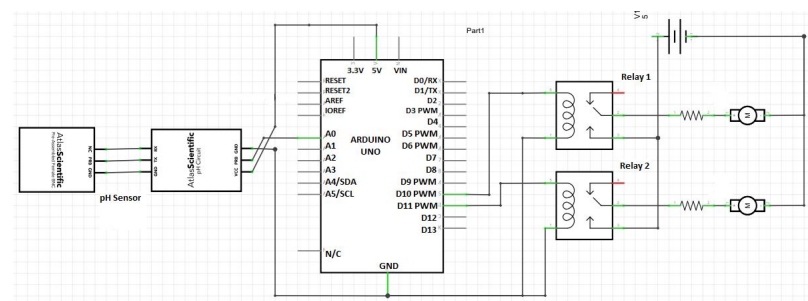

Figure 4: Full Circuit Design

Figure 5 shows the input of circuit design, where the $\mathrm{pH}$ sensor as an input component. From the $\mathrm{pH}$ circuit module, it has three wires out, which is Vcc, GND, and PRB. The Vcc wire connects to pin $5 \mathrm{v}$ at Arduino Uno board. Then, gnd wire to GND pin. Last, prb wire connects to A0 PIN for transmitting an analog signal from the $\mathrm{pH}$ sensor to a microcontroller for the signal processor.

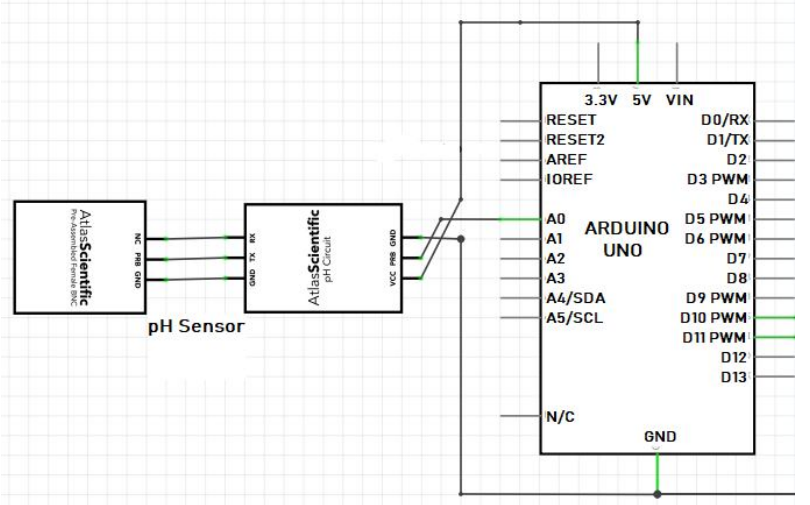

Figure 5: Input of Circuit Design

Figure 6 above shows the output circuit design. The relay is waiting for the trigger from Arduino Uno to switch on the water pump for controlling operation. The Relay 1 is set to 10 pins and Relay 2 is set to 11 pins on Arduino Uno Board. The supply of $5 \mathrm{v}$ is connected to relay to turn on the water pump when it receives trigger signal. The circuit is closed, and the water pump will turn on. The USB is connecting from Arduino Uno to a computer for transmitting and receiving the trigger signal and data transfer. The computer received the output from a microcontroller and displays the value at monitors.

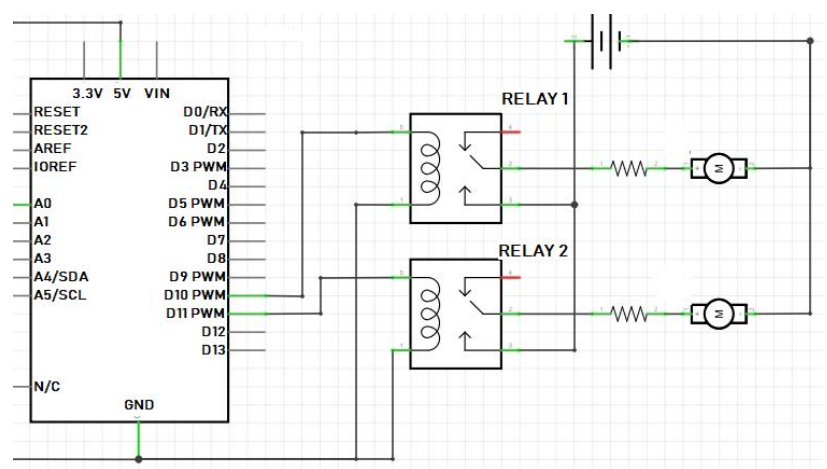

Figure 6: Output of Circuit Design

\section{RESULT AND DISCUSSION}

The result presents a prototype of System Interface that tracked the changes of $\mathrm{pH}$ level in water cause of water exposed to several causes on acidic rain.

\subsection{GUI System Interface}

The result presents $\mathrm{pH}$ level drops due to a high concentration of acid in water. The system presents features on monitoring and controlling operation. Figure 7 shows a screenshot of main graphical user interface (GUI). The figure shows the program before starting. Before the program starts, the user must choose COM port number in which Arduino Uno is connected via USB cable. After clicking 'Connect' button, the program will show COM port is connected and done accessed. The program can receive input from Arduino Uno. The real Time clock is activating through the operating system time. Then, the data received and displayed in 'Serial Monitor' textbox, 'Chart Monitor' graph and 'Monitor' progress bar.

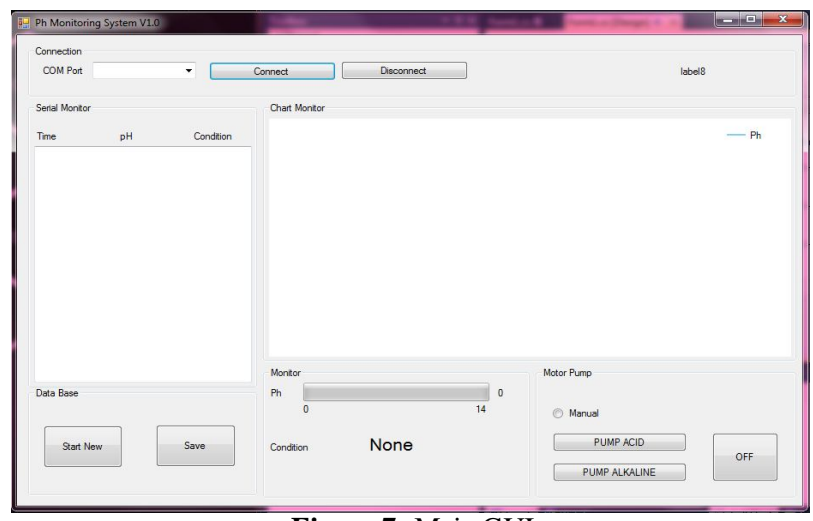

Figure 7: Main GUI

Figure 8 shows the program started after button 'Connect' clicked. Reading the $\mathrm{pH}$ level parameters is displayed on the screen from time to time for the farmers to view and track the current reading of the $\mathrm{pH}$ level in pond water. 


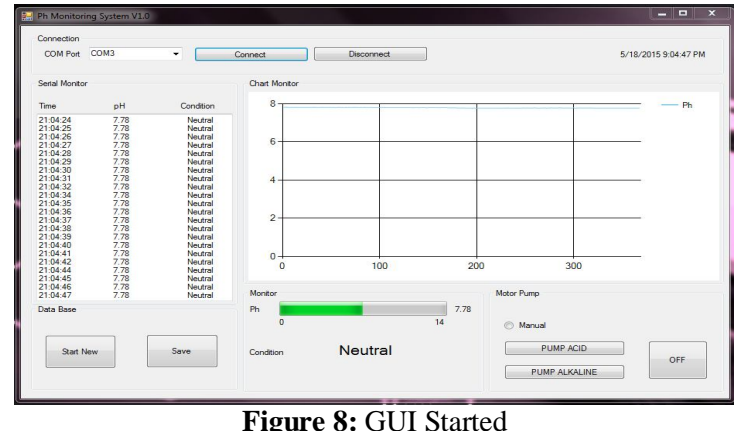

Figure 8: GUI Started

\subsection{Alert Interface}

Figure 9 shows the parameter readings are displayed in 'Serial Monitor' in real time, $\mathrm{pH}$ value and state condition of water in textbox, respectively. The date and time of the last update made imparted to users. All this info is pertinent to the farmers in knowing the latest condition of their pond. Other information shown on a screen includes the progress bar of the $\mathrm{pH}$ value at the moments. Figure 10 shows an indicator of $\mathrm{pH}$ value from 0 until 14 . Besides that, the status of $\mathrm{pH}$ level in water also shown on screen. The status divided into three types: Neutral, Acidic and Alkaline.

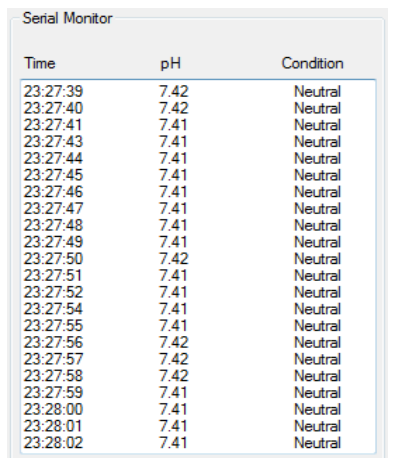

Figure 9: Serial Monitor Interface

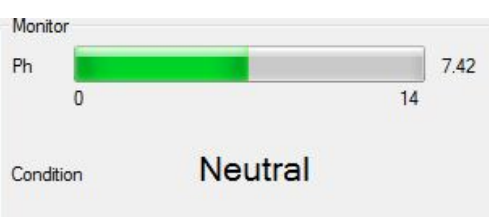

Figure 10: Monitor $\mathrm{pH}$ level Interface

The alert interfaces showing the exact reading of each parameter, the farmers can infer the parameter contributes to changes of $\mathrm{pH}$ level in the water. Thus, the users can take immediate and appropriate action before the condition of the pond gets worse. Figure 11 shows the interface where the users can maintain the water manually just click on the 'PUMP ACID' or 'PUMP ALKALINE' button. The 'OFF' button is to stop the operation of both water pumps.

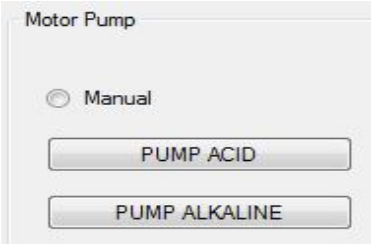

Figure 11: Motor water Pump Interface

\subsection{Recording Interface}

There a type of report that can be viewed as data recorded. Data recorded report keeps track of all the sensors reading from the starting program is started. There are three items are recorded in a report which is time, $\mathrm{pH}$ value and water status. Figure 12 shows if the button 'save' is clicked, it will save the recorded report in a specific folder and named the file by date and time. It is easing to the user the check back the previously recorded reading at the time in future. The sample recorded of reading is shown in Figure 13. It is saved in a text format file.

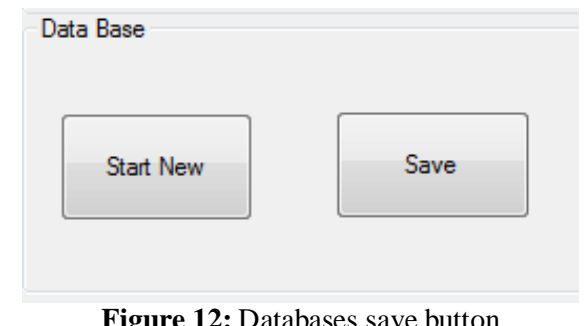

Figure 12: Databases save button

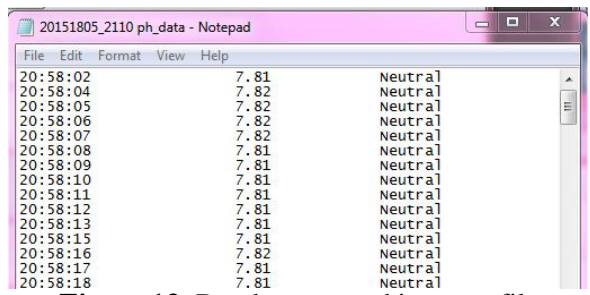

Figure 13: Databases saved in a text file

\subsection{Data Analysis on Water $\mathrm{pH}$ Level Readings}

Figure 14 show result of the changes $\mathrm{pH}$ level in the water for 90 seconds.

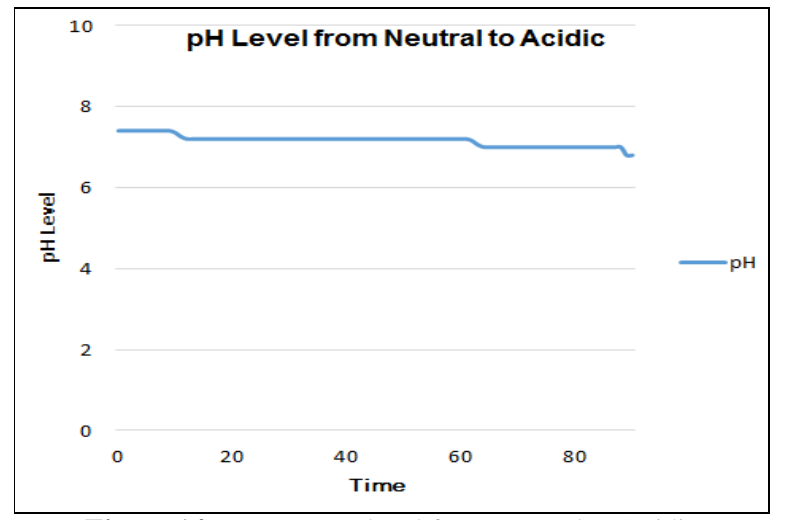

Figure 14: Data on $\mathrm{pH}$ level from Neutral to Acidic

The first 20 seconds show a dropped reading from 7.5 to 7 units. Towards the end time, reading shows nearly 6.3 units which is acidic level. This chart shows the changes in the $\mathrm{pH}$ level in water versus with time in seconds. Figure 15 shows a control from acidic back to neutral condition tested in 40 seconds. The Reading below 6.5 is shown from the started 13 seconds and grows up to neutral level that reached 7.7 units at the 20 seconds in time. The acidic level is controlled consistently at neutral stage until the last 43 seconds. This chart continuously shows the reading until the program is closed. 


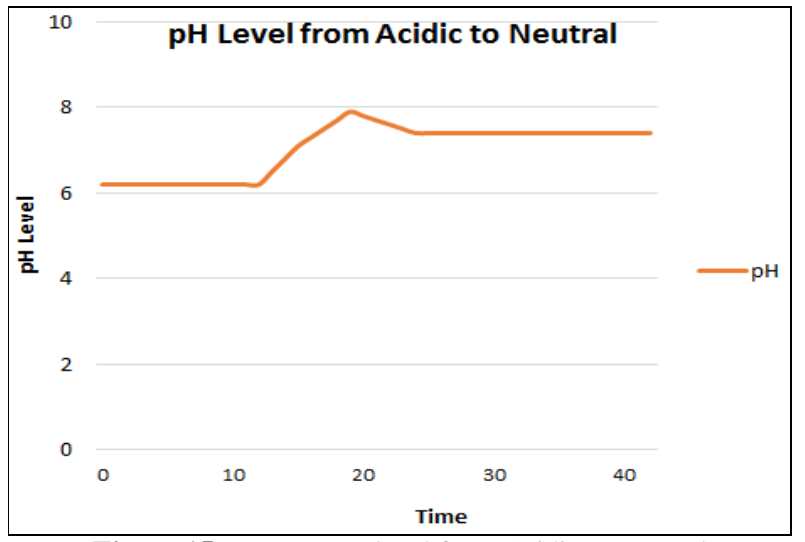

Figure 15: Data on $\mathrm{pH}$ level from Acidic to Neutral

\section{CONCLUSION}

As a conclusion, this system control and keep consistent $\mathrm{pH}$ level in water to helps aquaculture farmers in observing, controlling and monitor $\mathrm{pH}$ water. This system has overcome the manual system that observed a repetitive test and comprehensive examination due to humid and spacious farm. The prototype system helps automatic monitoring and control the water $\mathrm{pH}$ in a timely manner and alert farmers upon detecting degradation of $\mathrm{pH}$ level in the water. Result presents some control on Neutral to Acidic and vice versa actions on the $\mathrm{pH}$ levels of water for farm prawn breeding which increased the quality of service. Thus, the quality of aquaculture products will increase, and the usability testing implies that the system has proven to meet the specific needs of what the clients require. Some restrictions have been identified which the flow just monitor one parameter, which is a pH level. Next, more parameters are expected to acquire a progressively for an exact outcome. The proposed solution can also be further enhanced by allowing the system to detect the water quality suitable for various kind of aquaculture that suitable for prawn breeding system. An improvement can be made on the system includes adding prediction features into the system on water quality to proactively monitor and take pre-action that will affect the aquaculture systems.

\section{ACKNOWLEDGMENT}

Authors would like to thanks to Research Management Institute, Universiti Teknologi MARA, UiTM Shah Alam, Selangor for the support grant in publishing this paper.

\section{REFERENCES}

[1] N. S. Haron, M. K. Mahamad, I. A. Aziz, and M. Mehat, "Remote water quality monitoring system using wireless sensors," in Proceedings of the 8th WSEAS International Conference on Electronics, Hardware, Wireless and Optical Communications (EHAC'09), Cambridge, UK, 2009, pp. 148-154.

[2] R. Bórquez-Lopez, R. Casillas-Hernandez, J. LopezElias, R. Barraza-Guardado, and L. Martinez-Cordova, "Improving feeding strategies for shrimp farming using fuzzy logic, based on water quality parameters," Aquacultural Engineering, vol. 81, pp. 38-45, 2018.

https://doi.org/10.1016/j.aquaeng.2018.01.002
[3] I. Karplus and A. Barki, "Male morphotypes and alternative mating tactics in freshwater prawns of the genus Macrobrachium: a review," Reviews in Aquaculture, 2018.

[4] H. Rosly, "Garis panduan mutu air untuk ternakan ikan dan udang laut," Risalah Perikanan Bil, vol. 43, 1990.

[5] M. Zain, B. Aisham, M. F. Khasim, S. Md Salleh, and M. S. Wahab, "Design concept of two tank reservoirs to maintain $\mathbf{p H}$ value for tiger prawn," Applied Mechanics and Materials, vol. 660, pp. 851-856, 2014.

[6] P. Jiang, H. Xia, Z. He, and Z. Wang, "Design of a water environment monitoring system based on wireless sensor networks," Sensors, vol. 9, pp. 64116434, 2009. https://doi.org/10.3390/s90806411

[7] B. K. Jha, G. G. Sivasankari, and K. R. Venugopal, "Cloud-based smart water quality monitoring system using iot sensors and machine learning," International Journal of Advanced Trends in Computer Science and Engineering, vol. 9, pp. 3403-3409, 2020. https://doi.org/10.30534/ijatcse/2020/141932020

[8] M. Prasad, S. Majeed, S. Romichan, W. Mathew, and P. Udaybabu, "Cost effective IoT based automated fish farming system with flood prediction," International Journal of Advanced Trends in Computer Science and Engineering, vol. 9, pp. 291-297, 2020.

https://doi.org/10.30534/ijatcse/2020/4491.32020

[9] A. R. Benito, "Enhanced decision support system for automated fish feeder and water quality detection with SMS notification," International Journal of Advanced Trends in Computer Science and Engineering, vol. 9, pp. 215-221, 2020. https://doi.org/10.30534/ijatcse/2020/3291.32020

[10] Syaharuddin, D. Pramita, T. Nusantara, and Subanji, "Computational of distribution of wind speed as preliminary information for fishers: Case study in lombok sea," International Journal of Advanced Trends in Computer Science and Engineering, vol. 9, pp. 3584-3587, 2020. https://doi.org/10.30534/ijatcse/2020/165932020

[11] R. V. Sevilla, A. C. Fajardo, and R. A. Diamante, "Milkfish freshness detection utilizing Coiflet wavelet transform method," International Journal of Advanced Trends in Computer Science and Engineering, vol. 8, pp. 1174-1180, 2019. https://doi.org/10.30534/ijatcse/2019/27842019

[12] C. Negrini, C. S. d. Castro, A. T. B. Guimarães, A. Frozza, R. O. Kracizy, and E. L. C. Ballester, "Stocking density for freshwater prawn Macrobrachium rosenbergii in biofloc system," Submission article platform-Latin American Journal of Aquatic Research, vol. $45,2018$.

[13] A. O. o. t. U. N. F. Department, The State of World Fisheries and Aquaculture, 2000 vol. 3: Food \& Agriculture Org., 2000.

[14] B. A. M. Zain, F. F. Anuar, and N. Al-Shaibani, "Comparative Study on Flexible Link Aerator Using Arduino Programming and Dissolved Oxygen Meter," International Journal of Integrated Engineering, vol. 10, 2018.

[15] A. H. Mustafa Kamal, O. Hishamuddin, and C. E. Boyd, "Physical and chemical characteristics of soil from tiger shrimp aquaculture ponds at Malacca, 
Malaysia," Journal of Applied Aquaculture, vol. 30, pp. 47-62, 2018.

[16] L. da Silva, Z. Yang, N. Pires, T. Dong, H.-C. Teien, T. Storebakken, et al., "Monitoring Aquaculture Water Quality: Design of an Early Warning Sensor with Aliivibrio fischeri and Predictive Models," Sensors, vol. 18, p. 2848, 2018. https://doi.org/10.3390/s18092848

[17] R. Diwate, S. Chavan, P. Dabhade, and P. Sangale, "Automatic Water Pollution Control and Filtration System for Rivers Using IOT," International Journal, vol. 3, 2018.

[18] M. Kassim, M. Ismail, and C. C. K. Yahaya, "A Web Based Temperature Monitoring System," International journal of multidisciplinary sciences and engineering, vol. 2, pp. 1-9, 2011.

[19] Omega. (2019, Introduction to pH. Omega Technical Report: $p H$ Reference, 1-3. 